\title{
The role of ultrasound in evaluating salivary glands swellings
}

Abd El-latif Ibrahim El-Rasheedy ${ }^{1}$, Alaa Mohamed Abdel Rasoul Abdalla* , Shaimaa Abdel-hamid Hassanein², Tarek Abdel Rahman Abdel Hafez ${ }^{1}$ and Heba Abdel-rehem Aboel-naga'

\begin{abstract}
Background: Viral infection is the most common cause of salivary gland swelling as mumps which mainly affects the parotid glands. Sialolithiasis is another cause of obstruction of the salivary duct. A tumor is another cause of swelling. Around $70 \%$ of salivary gland tumors arise from the parotid glands. Benign lesions represent $57 \%$ of these tumors. Three to $5 \%$ of all tumors affecting the head and neck are represented in the salivary gland.

Ultrasonography is considered a basic diagnostic tool in all salivary gland swellings. Our study is to evaluate the role of ultrasound in the evaluation of salivary glands swellings in comparison with a computed tomography scan.

Results: A total of 80 patients aged more than 1 year old with swellings affecting the salivary glands were collected from the out-patient clinic during the period from February 2020 to February 2021. All patients underwent ultrasonography and computed tomography examination of the neck. All submandibular gland lesions presented with sialolithiasis (40 cases) (100\%), and 20 cases (50\%) of parotid gland swellings presented as inflammation without stone (16 cases (40\%) of acute inflammation and 4 cases (10\%) with recurrent inflammation), while 4 patients only presented as sialolithiasis. Neoplastic lesions were diagnosed in 16 cases of the parotid gland group. Stones less than $3 \mathrm{~mm}$ were detected only by computed tomography in 5 patients (12.5\%) of the submandibular group. Twenty-eight cases (70\%) with stones ranged in size between 3 and $6 \mathrm{~mm}$. Only 11 cases (27.5\%) with stones ranged in size more than $6 \mathrm{~mm}$. Of the 16 parotid swellings diagnosed with neoplastic lesions, 14 parotid cases (87\%) showed well-defined margins by computed tomography and ultrasonography.
\end{abstract}

Conclusions: Sonography is the basic diagnostic tool in salivary glands swellings. Ultrasonography should be the initial imaging modality. Only in special cases, such as stones that could not be detected by ultrasonography or a neoplastic lesion in a deep location, or bone infiltration, computed tomography neck should be performed.

Keywords: Parotid, Submandibular gland, Ultrasonography

\footnotetext{
* Correspondence: dr.minds_invader@yahoo.com

'Department of Otorhinolaryngology, Menoufia University, Shebeen El-Kom,

El-Menoufia, Egypt

Full list of author information is available at the end of the article
}

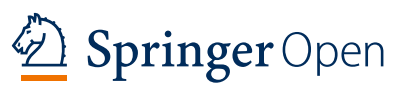

(c) The Author(s). 2021 Open Access This article is licensed under a Creative Commons Attribution 4.0 International License, which permits use, sharing, adaptation, distribution and reproduction in any medium or format, as long as you give appropriate credit to the original author(s) and the source, provide a link to the Creative Commons licence, and indicate if changes were made. The images or other third party material in this article are included in the article's Creative Commons licence, unless indicated otherwise in a credit line to the material. If material is not included in the article's Creative Commons licence and your intended use is not permitted by statutory regulation or exceeds the permitted use, you will need to obtain permission directly from the copyright holder. To view a copy of this licence, visit http://creativecommons.org/licenses/by/4.0/. 


\section{Background}

Mumps is one of the viral infections of the salivary gland and the most common cause for salivary gland swellings. Sialolithiasis is one of the causes of bacterial infection affecting the salivary gland clinically presented as enlarged and tender lymph nodes of the neck and pus formation of the infected salivary gland. A tumor is another cause of swelling. Around $70 \%$ of salivary gland tumors arise from the parotid glands. Benign lesions represent $57 \%$ of these tumors. Three to $5 \%$ of all tumors affecting the head and neck are represented in salivary gland tumors [1].

Ultrasound is the initial imaging method for salivary gland swellings. The deep lobe of the parotid is difficult to be examined using ultrasound (U/S). U/S has higher accuracy in delineating benign and malignant salivary gland tumors [2].

In acute inflammation, we use ultrasound to look for sialolithiasis or abscesses. Ultrasound is highly sensitive in detecting sialolithiasis and replaced sialography in many institutions. Sialoliths can be detected by a variety of tests such as radiographic sialography with iodinated contrast material, sonography, computed tomography, magnetic resonance sialography, cone-beam computed tomography, and sial-endoscopy; all of these methods are invasive or require X-ray exposure except for ultrasound and magnetic resonance sialography. Radiographic sialography is considered the reference standard for assessing the pathologic conditions in the salivary ducts, including lithiasis. Radiographic sialography is contraindicated in patients having an acute salivary infection, so ultrasound is preferred in these cases [3].

Detection of salivary gland stones by computed tomography depends on whether calcium exists or not in the calculi. Magnetic resonance imaging is a nonirradiating alternative imaging modality for the assessment of ductal pathologies without the risk of radiation or cannulation of the duct, but magnetic resonance sialography is much more expensive and not available in most health care units. It showed sensitivities and specificities of $80-100 \%$ and $90-100 \%$ in the detection of sialolithiasis [4].

Our study is to evaluate the role of ultrasound in the evaluation of salivary gland swellings in comparison with a computed tomography scan.

\section{Methods}

During the period from February 2020 to February 2021, our prospective study was carried on 80 patients with swellings affecting the salivary glands. Written consent was taken from all patients.

Patients aged more than 1 year old with salivary gland swellings were included in this study while patients with previous neck surgery or underwent radiation or chemotherapy were excluded from our study. All patients were subjected to full history taking and full clinical examinations.

All patients underwent ultrasonography and computed tomography examination of the neck. Ultrasound examination of the neck was performed including examination of both parotids and submandibular glands with emphasis on the site of the swelling. Patients were examined in the supine position with a mild tilt of the head upwards when examining the submandibular glands and to the contralateral side when examining the parotid gland.

1. Ultrasonographic examinations were performed by an experienced radiologist using the superficial linear probe of a high-quality ultrasound machine with a frequency of 7-14 MHz depending on the site examined. Each salivary gland was evaluated in at least two perpendicular planes for its size, echogenicity, and presence of stones or masses. Then, the whole neck was scanned to assess the lymph nodes and search for concomitant or related diseases.

2. Multi-detector computed tomography examination of the neck was performed for all patients with or without contrast according to the suspected pathology. Patients were examined in the supine position with the scan covering from the base of the skull to the aortic arch. Intravenous iodinated contrast media was used in cases suspected of neoplasm in a dose of $1 \mathrm{ml} / \mathrm{kg}$ with a maximum of $70 \mathrm{ml}$ with an injection rate of $2 \mathrm{~mm} / \mathrm{s}$. Axial volume was taken with a thickness of $2.5 \mathrm{~mm}$ and then transferred to a workstation where multiplanar reconstruction was performed to obtain coronal and sagittal images of the glands. Each gland was assessed for stones or masses and compared to the ultrasound findings.

All statistical analyses were performed at a 5\% confidence interval, and a $p$-value $<0.05$ was considered significant. The statistical software packages Statistical Package of the Social Sciences 15.0 (SPSS Inc., Chicago, IL, USA) were used for the analysis of the data. In addition to the standard descriptive statistical calculations as mean and standard deviation (SD), the results on categorical measurements were presented in numbers (\%).

\section{Results}

A total of 80 patients with salivary gland swelling were included in our research that were divided into two groups. Group 1 included patients with parotid gland swellings (40 patients). Group 2 included patients with submandibular gland swellings (40 patients). Most of our patients were females representing $60 \%$ of the study group. Their epidemiological characteristics are grouped in Table 1. 
Table 1 Patient characteristics

\begin{tabular}{lll}
\hline Patient data & No. (\%) \\
\hline Age & Mean \pm standard deviation $=36.3 \pm 12.4$ \\
Sex & Male & $32(40 \%)$ \\
& Female & $48(60 \%)$ \\
\hline
\end{tabular}

Table 2 shows all submandibular gland lesions presented with sialolithiasis (40 cases) (100\%), and 20 cases (50\%) of parotid gland swellings presented as inflammation without stone (16 cases $(40 \%)$ of acute inflammation and 4 cases (10\%) with recurrent inflammation), while 4 patients only presented as sialolithiasis. Neoplastic lesions were diagnosed in 16 cases of the parotid gland group.

Table 3 shows that stones less than $3 \mathrm{~mm}$ were detected only by computed tomography in 5 patients $(12.5 \%)$ of the submandibular group. Twenty-eight cases (70\%) with stones ranged in size between 3 and $6 \mathrm{~mm}$. Only 11 cases $(27.5 \%)$ with stones ranged in size more than $6 \mathrm{~mm}$ as shown in Figs. 1 and 2. The sensitivity and specificity of U/S in detecting stones at submandibular or parotid glands are $88.6 \%$ and $100 \%$, respectively.

Table 4 shows 16 parotid swellings diagnosed with neoplastic lesions appeared as hypoechoic masses in the ultrasound and hypodense masses in the computed tomography (CT), and 14 parotid cases showed well-defined margins by $\mathrm{CT}$ and U/S. Enlarged lymph nodes appeared in only 2 cases by either CT or U/S, but only one case showed invasion to the surrounding that was not detected by the U/S as shown in Fig. 3.

\section{Discussion}

The imaging diagnosis of salivary gland tumors is still a matter of controversy either by ultrasonography or computed tomography. Tumors with a diameter of less than $1 \mathrm{~cm}$ and isodense masses can escape from the diagnostic tools. As well as small salivary gland stones cannot be obvious by available imaging studies [2].

Recent publications revealed that high-definition sonography of structures close to the surface reports a comparable or even higher sensitivity compared to computed tomography [3].

The superficial location of different salivary glands makes their lesions better shown by high-resolution ultrasound especially with a probe having a frequency of

Table 2 The nature of salivary gland swellings

\begin{tabular}{lll}
\hline The nature of salivary & \multicolumn{2}{l}{ No. of cases $=\mathbf{8 0}$} \\
\cline { 2 - 3 } gland swellings & Parotid group & Submandibular group \\
\hline Sialolithiasis & 4 & 40 \\
Inflammation without stone & 20 & - \\
Neoplasm & 16 & - \\
\hline
\end{tabular}

Table 3 Relation of stone size and its detection in 44 cases

\begin{tabular}{lll}
\hline Stone size & Total cases $=\mathbf{4 4}$ \\
\cline { 2 - 3 } & U/S & CT \\
\hline - Less than $\mathbf{3} \mathbf{~ m m}$ & - & 5 \\
- 3-6 $\mathbf{m m}$ & 28 & 28 \\
- More than $6 \mathrm{~mm}$ & 11 & 11 \\
\hline
\end{tabular}

5-12 MHz. U/S should be done bilaterally in paired glands as the same session in longitudinal and horizontal levels at least [2].

The not visible part of the parotid gland such as the deep lobe and the infra-mandibular part using U/S need other methods like magnetic resonance imaging or computed tomography in the presence of pathologic changes in these areas [5].

Our study included a total of 80 patients with salivary gland swelling that were divided into two groups: the parotid gland lesion group (40 patients) and the submandibular gland group (40 patients). There were 44 cases $(55 \%)$ of sialolithiasis (40 cases $(90 \%)$ of the submandibular gland group and 4 cases $(10 \%)$ only of the parotid gland group). Neoplastic lesions were diagnosed in 16 cases (15\%) of parotid origin, and 20 cases (50\%) of parotid origin were diagnosed as acute inflammation in 16 cases (40\%) and recurrent inflammation in 4 cases (10\%). Rinast et al. made a study over 35 parotid lesions and diagnosed 8 cases (17\%) only with sialolithiasis and 27 cases (77\%) with parotid mass (11 pleomorphic adenoma, 5 cystadenoma, 5 lymphoma, and 6 other lesions) [6].

The viscous nature of the submandibular gland secretion makes it more liable to stone formation than the serous secretion of the parotid glands. Ultrasound should be the initial examination in the assessment of salivary gland calculi because of its advantages of being noninvasive and low in cost [4].

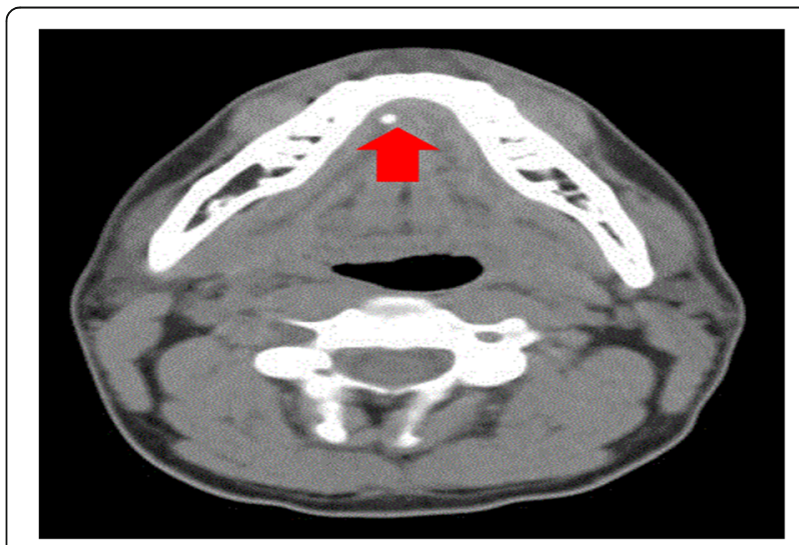

Fig. 1 CT scan neck axial view without contrast showing a 2-mm right submandibular gland stone that was not detected by U/S (red arrow) 


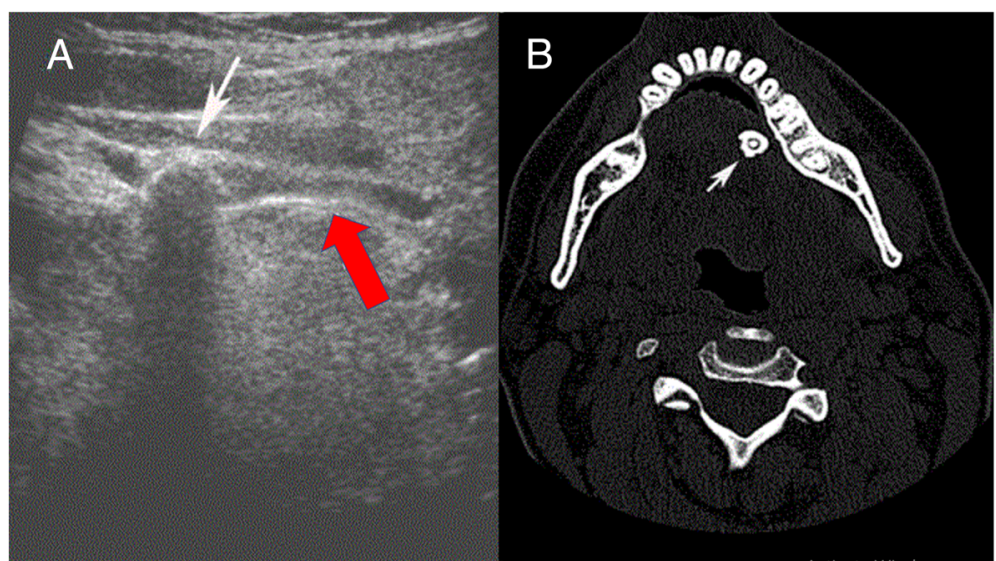

Fig. $2 \mathrm{U} / \mathrm{S}$ and $C T$ neck show the left submandibular gland stone. A U/S neck showing a stone in the left submandibular gland (white arrow) about $1 \mathrm{~cm}$ and the dilatation of the duct (red arrow). B CT scan neck axial view showing the stone in the left submandibular gland measuring about $1 \mathrm{~cm}$ (white arrow)

Terraz et al. in 2013 made a study on 53 calculi diagnosed in 44 salivary glands (11 parotid glands and 33 submandibular glands). The majority of the cases (57\%) showed salivary gland stones greater than $3 \mathrm{~mm}$. Twenty-three percent of the studied cases showed stones with a diameter less than $3 \mathrm{~mm}$ in ten glands, and $20 \%$ of these cases showed stones with a diameter of $3 \mathrm{~mm}$ in nine glands. Therefore, whenever a stone was detected by ultrasound, it was considered true-positive for sialolithiasis [1].

Also, in our study, the results of ultrasound done by Terraz et al. in 2013 for assessment of salivary gland stones included 34 true-positive and 36 true-negative readings. Ten glands showed false-negative results, and two glands showed false-positive readings. Ten salivary gland stones could be detected by U/S, because the size of these stones showed by CT were less than $3 \mathrm{~mm}$ in diameter. U/S could show just acoustic shadow or ductal dilatation in these lesions [1].

Gritzmann in 1989 reported 94\% sensitivity of ultrasound of the major salivary glands, but the size of the calculi was not reported with sonography, while Diederich et al. in 1987 reported only $71 \%$ sensitivity. Jager et al. in 2000 reported $80 \%$ sensitivity in 20 patients with suspected submandibular gland sialolithiasis [7-9].

Table 4 Radiological findings in cases diagnosed as neoplasm

\begin{tabular}{llll}
\hline Parotid group & \multicolumn{2}{l}{ No. of cases $\mathbf{1 6}$} \\
\cline { 3 - 4 } & & U/S & CT \\
\hline Findings & Well-defined & 14 & 14 \\
& III-defined & 2 & 2 \\
& Enlarged lymph nodes & 2 & 2 \\
& Invasion to surroundings & - & 1 \\
\hline
\end{tabular}

About 3\% of head and neck tumors arise from the salivary gland, which remains asymptomatic until growing to a great size or invading neighboring structures, such as the muscles, nerves, or ducts, where they are superficially located and easy to be detected. It is difficult to identify certain lesions such as deep located tumors or tumors. Some imaging modalities such as U/S, CT, and magnetic resonance imaging (MRI) are necessary for clinical diagnosis [10].

In a study conducted by Lee et al. in 2008, they searched for the diagnostic accuracy of the ultrasound, computed tomography, and magnetic resonance imaging modality in salivary gland tumors. They detected that there was no statistical difference among these modalities in assessing salivary gland tumor lesions [10].

Benign lesions at the salivary glands are more common than malignant lesions (3\%). U/S could help in the diagnosis of these tumors. During the diagnostic ultrasound in the salivary gland tumors patients, characteristics like lesion size, echogenicity vascularity, and the margin should be considered; moreover, other data should be in mind during the diagnosis like history, growth speed, and VII nerve affection. For cases such as deep lobe mass, it is difficult for an ultrasound to do differential diagnosis [11].

Rudack et al. showed that the chi-square test showed no significant difference between computed tomography, ultrasound, and MRI. The diagnosis could be the same using different salivary gland imaging techniques when done for the benign salivary gland lesions while in malignant lesions, CT should be used to assess the invasion of the surrounding structures [12].

In assessing benign salivary gland tumors, Kinoshita et al. showed that the sensitivity of ultrasound in the detection of salivary gland lesions was $88 \%$, and its 


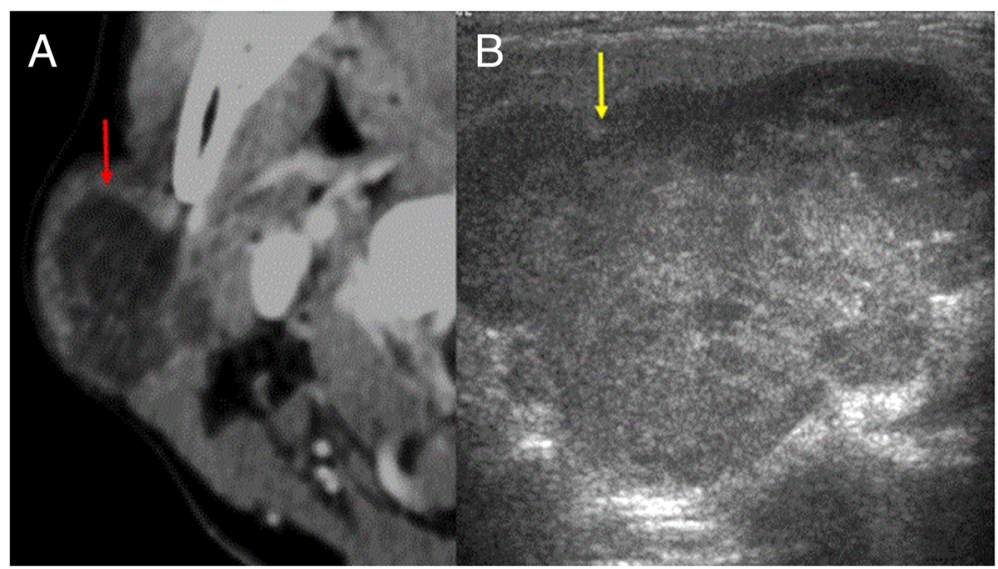

Fig. 3 Well-defined lobulated mass in the right parotid gland. A Post-contrast CT axial image shows a lobulated low-density mass in the right parotid gland which mimics a cystic lesion suggesting benign neoplasm (red arrow). B U/S shows homogeneously solid and shows well-defined lobulated margins (yellow arrow)

accuracy was $79 \%$, but the specificity of this imaging technique was $54 \%$. Another study reported the accuracy of ultrasound was $82 \%$, in benign tumors [13].

Computed tomography in the study offered by Kinoshita et al. showed $45 \%$ of cases with the right diagnosis. In malignant lesions, ultrasound could forecast the correct diagnosis in 4 of 30 cases (13\%). Ultrasound showed $54 \%$ specificity in benign salivary gland lesions, whereas malignant salivary gland tumors could need multiple imaging techniques to reach the right diagnosis [13].

\section{Conclusions}

Ultrasound is the investigation of choice in salivary gland swellings. Computed tomography could be needed in certain cases such as deep parotid gland lesions or sialolithiasis with small stones in the ducts of the salivary glands. Computed tomography should be done in cases suspected of malignant salivary gland lesions.

\section{Abbreviations}

CT: Computed tomography; U/S: Ultrasonography; MRI: Magnetic resonance imaging

\section{Acknowledgements}

Not applicable

\section{Authors' contributions}

$\mathrm{AE}$ analyzed and interpreted the patient data regarding the diagnosis of the cases and was the main supervisor on the work. SH contributed to the radiological assessment of the cases. HA performed the analysis of the data. TA and AA were the major contributors in writing the manuscript. All authors read and approved the final manuscript.

\section{Funding}

There was no funding

\section{Availability of data and materials}

The datasets used and/or analyzed in the current study are available from the corresponding author on reasonable request.

\section{Declarations}

Ethics approval and consent to participate

A written consent was taken from the patients before performing the radiological assessment of the cases, and they had the right to refuse at any time. The study was approved by the Research Ethics Committee of the Faculty of Medicine, Menoufia University. The ethics committee reference number is $2 / 2020$ ENT/53.

\section{Consent for publication}

Not applicable

\section{Competing interests}

The authors declare that they have no competing interests.

\section{Author details}

'Department of Otorhinolaryngology, Menoufia University, Shebeen El-Kom, El-Menoufia, Egypt. ${ }^{2}$ Department of Radiology, Menoufia University, Shebeen El-Kom, Egypt.

Received: 24 April 2021 Accepted: 8 September 2021

Published online: 06 October 2021

\section{References}

1. Terraz S, Poletti AP, Dulguerov P, Dfouni N, Becker CD, Marchal F et al (2013) How reliable is sonography in the assessment of sialolithiasis? AJR 201(1):104-109. https://doi.org/10.2214/AJR.12.9383

2. Zengel P, Schrotzlmair F, Reichel C, Paprottka P, Clevert DA (2013) Sonography: the leading diagnostic tool for diseases of the salivary glands. Semin Ultrasound CT MRI 34(3):196-203. https://doi.org/10.1053/j.sult.2 012.11 .012

3. Abdel Razek AAK, Mukherji SK (2018) State-of-the-art imaging of salivary gland tumors. Neuroimaging Clin N Am 28(2):303-317. https://doi.org/10.1 016/.nic.2018.01.009

4. Witt RL, Iro H, Koch M, McGurk M, Nahlieli O, Zenk J (2012) Minimally invasive options for salivary calculi. Laryngoscope 122(6):1306-1311. https:// doi.org/10.1002/lary.23272

5. Jecker P, Orloff LA (2009) Salivary gland ultrasonography. In: Orloff LA (ed) Head and neck ultrasonography. Plural Publishing, San Diego, pp 129-152

6. Rinast $E_{1}$ Gmelin $E_{1}$ Barbara HT (1990) Imaging diagnostics for parotid diseases - em method comparison. Laryngo-Rhino-Otol. 69(09):460-463. https://doi.org/10.1055/s-2007-998230

7. Gritzmann N (1989) Sonography of the salivary glands. AJR 153(1):161-166. https://doi.org/10.2214/ajr.153.1.161

8. Diederich S, Wernecke K, Peters PE (1987) Sialographic and sonographic diagnosis of diseases of the salivary gland. Radiologe. 27(6):255-261 
9. Jager L, Menauer F, Holzknecht N, Scholz V, Grevers G, Reiser M (2000) Sialolithiasis: MR sialography of the submandibular duct-an alternative to conventional sialography and U/S? Radiology 216(3):665-671. https://doi. org/10.1148/radiology.216.3.ro0se12665

10. Lee YY, Wong KT, King AD, Ahuja AT (2008) Imaging of salivary gland tumours. Eur J Radiol 66(3):419-436. https://doi.org/10.1016/j.ejrad.2008.01.027

11. Li LJ, Li Y, Wen YM, Liu H, Zhao HW (2008) Clinical analysis of salivary gland tumor cases in West China in past 50 years. Oral Oncol 44(2):187-192. https://doi.org/10.1016/j.oraloncology.2007.01.016

12. Rudack C, Jörg S, Kloska S, Stoll W, Thiede O (2007) Neither MRI, CT nor U/S is superior to diagnose tumors in the salivary glands - an extended case study. Head Face Med 3:19

13. Kinoshita T, Ishii K, Naganuma H, Okitsu T (2004) MR imaging findings of parotid tumors with pathologic diagnostic clues: a pictorial essay. Clin Imaging 28(2):93-101. https://doi.org/10.1016/S0899-7071(03)00120-7

\section{Publisher's Note}

Springer Nature remains neutral with regard to jurisdictional claims in published maps and institutional affiliations.

\section{Submit your manuscript to a SpringerOpen ${ }^{\circ}$ journal and benefit from:}

- Convenient online submission

- Rigorous peer review

- Open access: articles freely available online

High visibility within the field

- Retaining the copyright to your article

Submit your next manuscript at $\boldsymbol{\wedge}$ springeropen.com 